\title{
Quality of life for kidney transplant recipients and hemodialysis patients in Palestine: a cross-sectional study
}

\author{
Adnan Lutfi Sarhan', Raya H. Jarareh² and Mujahed Shraim ${ }^{3^{*}}$ (D)
}

\begin{abstract}
Background: Health related quality of life (HRQOL) is an important indicator of medical treatment and is a strong predictor of disability and mortality. The literature has shown mixed evidence about whether kidney transplantation improves HRQOL compared with other renal replacement modalities. The aim of this study was to compare the HRQOL in kidney transplant recipients (KTRs) and hemodialysis (HD) patients.

Methods: A cross-sectional study of 100 KTRs and 272 HD patients from two central kidney units in the West Bank, Palestine. The HRQOL was assessed using the Short Form-36 Health Survey. Multivariable linear regression was used to estimate differences in mean HRQOL scores between KTRs and HD patients.

Results: As compared to HD patients, KTRs had higher clinically important HRQOL in main domains and subscales of the SF-36 including physical functioning, role-physical, bodily pain, general health, vitality, social functioning, roleemotional, mental health, ranging between 15.5 for social functioning (95\% Confidence Interval (Cl) 10.1, 20.7) to 32.6 for general health $(95 \% \mathrm{Cl} 24.0,41.1)$.

Conclusions: We found that KTRs have better HRQOL than HD patients in physical and mental components of the SF-36 scale including physical functioning, role-physical, bodily pain, general health, vitality, social functioning, roleemotional, and mental health. Further longitudinal research comparing HRQOL among KTRs and the general population may identify key modifiable factors associated with lower HRQOL among KTRs that are amenable to intervention.
\end{abstract}

Keywords: Quality of life, Renal Dialysis, Kidney transplantation, Cross-sectional studies

\section{Background}

Chronic kidney disease (CKD) is a growing global public health problem in terms of mortality, disability, and financial costs $[1,2]$. Globally, around $13 \%$ of the general population have some form of CKD [3]. In 2016, around 1.2 million deaths and 35 million disability-adjusted life years were attributed to CKD globally, which represents an increase in mortality and disability by 98 and $62 \%$

\footnotetext{
* Correspondence: mshraim@qu.edu.qa

${ }^{3}$ Department of Public Health, College of Health Sciences, QU Health, Qatar University, PO Box. 2713, Doha, Qatar

Full list of author information is available at the end of the article
}

since 1990, respectively [4]. A significant proportion of patients with CKD progress to end stage renal disease $[5,6]$. Currently, renal dialysis and kidney transplantation are the only two types of treatment available for patients with end stage renal disease [7]. Globally, the number of dialysis patients is projected to increase to 4.9 million by 2030 [8]. According to the Global Observatory on Donation and Transplantation, 100,097 kidney transplants were performed worldwide in 2019, which reflects an increase of $4.8 \%$ since $2018[9,10]$.

The literature suggests that kidney transplantation improves survival rates among patients on renal 
replacement therapy [11, 12]. However, kidney transplantation requires long-term immunosuppressive therapy, which is associated with significant side effects (such as recurrent infection, metabolic disorder, renal toxicity, fatigue, and poor self-perception of physical appearance) that may negatively affect patient's healthrelated quality of life (HRQOL) [13-16]. HRQOL is a significant independent predictor of hospitalization and mortality in patients on renal replacement therapy [17, 18]. HRQOL remains an important health outcome measure in renal transplantation recipients and in dialysis patients, which help clinicians and patients make rational decisions about the optimal choice of treatment modality. The literature shows mixed findings regarding whether kidney transplantation is associated with clinically important improvement in HRQOL [19-21]. In addition, research findings indicate that HRQOL among kidney transplant recipients (KTRs) is influenced by diverse factors, including perceived health status, mental health, and socioeconomic factors [15, 22, 23]. Research examining HRQOL among KTRs and hemodialysis (HD) patients in the Middle East is sparse. The aim of this study was to compare the HRQOL in KTRs and HD patients in the West Bank, Palestine.

\section{Methods}

\section{Design, setting and patient recruitment}

A cross-sectional study was conducted among KTRs and HD patients from two kidney dialysis units in the West Bank (Palestine Medical Complex in Ramallah and AnNajah National University Hospital in Nablus) between May and August 2017. The total number of kidney dialysis patients in these two units $(n=451)$ represented about $37 \%$ of all kidney dialysis patients $(n=1216)$ in the West Bank in 2017 [24]. HD patients were eligible to participate in the study if they were 18 years old or over and were undergoing HD for at least three months. KTRs were eligible to participate in the study if they were 18 years old or over and had functioning kidney transplant for at least on year. All eligible patients were invited to participate in the study while they were attending to their scheduled HD sessions or their outpatient follow-up visits. All patients who agreed to participate in the study signed a written informed consent and completed a self-reported questionnaire, which collected data on sociodemographic variables and HRQOL. The study was ethically approved by An-Najah National University Institutional Review Board.

\section{Sociodemographic variables}

The following variables were collected: age (18-29, 3060 , and $>60$ years), gender (female, male), education level (elementary, primary, secondary, and $>$ secondary education), and residential area (city, village, and refugee camp), and renal replacement therapy type (kidney transplantation or $\mathrm{HD}$ ).

\section{Assessment of HRQOL}

The Arabic version of the 36-Item Short Form Health Survey (SF-36) [25] was used to measure participants' perceived HRQOL. The SF-36 self-report survey is a widely used instrument to assess perceived HRQOL, which has been validated in several languages including Arabic [26, 27]. The SF-36 has been used to study HRQOL in people with different health conditions including KTRs and HD patients [28, 29]. The SF-36 assesses different domains of HRQOL using eight subscales (physical functioning, role-physical, bodily pain, general health, vitality, social functioning, roleemotional, and mental health) and two component summary measures are derived from the eight subscales (physical component summary (PCS) and mental component summary (MCS)). The PCS represents a summary of physical functioning, role-physical, bodily pain, and general health, where the MCS represents a summary of vitality, social functioning, role-emotional and mental health subscales. The number of questions pertaining to each subscale range from two for bodily pain and social functioning to ten for physical functioning, and the number of responses to each question ranges from two options (yes, no) to six-point Likert scale (none, very mild, mild, moderate, severe, and very severe). Each response option is numerically coded and then converted into a score of 0 to 100 . A mean score for each subscale and the two component summary measures is computed, with higher mean scores indicating better perceived HRQOL [25].

\section{Statistical analysis}

Numbers with percentages were used to summarize sociodemographic variables. The chi-square test was used to examine if there are any statistically significant differences in sociodemographic variables between KTRs and HD patients. The renal replacement therapy type (Kidney transplantation or hemodialysis) and sociodemographic characteristics were modeled as predictors of raw mean scores of SF-36 subscales, PCS, and MCS. Multivariable linear regression was used to assess the relationships between sociodemographic variables and PCS and MCS scores among KTRs and HD patients separately. Similarly, multivariable linear regression was used to assess if there were any differences in HRQOL scores between KTRs and HD patients while adjusting for sociodemographic characteristics. The HRQOL scores for all subdomains, PCS and MCS were not normally distributed. Therefore, we used bootstrap sampling and estimation method, with 1000 repetitions, in all regression analyses. All inferential statistical tests were 
two-sided. A $P$-value less than 0.05 was considered statistically significant. All analyses were performed using IBM SPSS Statistics computer program (version 26.0, IBM Corp).

\section{Results}

Three hundred and seventy-two patients participated in the study (100 KTRs (26.9\%) and $272 \mathrm{HD}$ patients). The sociodemographic characteristics differed significantly between the two groups for all variables except for residential area (Table 1). KTRs were younger than HD patients; 36 and $6.3 \%$ of KTRs and HD patients aged 1829 years, respectively. About 75 and $58.1 \%$ of KTRs and HD patients were males, respectively. Higher proportion of KTRs (72\%) obtained secondary school education or higher compared to HD patients (39.3\%).

\section{Sociodemographic factors associated with HRQOL among KTRs and HD patients}

Studying detailed associations between sociodemographic variables and HRQOL scores at SF-36 subscales level was not the focus of the current study. Therefore, we report here only adjusted associations between sociodemographic variables and PCS and MCS scores (detailed data on this is available from the authors upon reasonable request). As shown in Table 2, HD patients aged more than 60 years had significantly lower PCS and MCS scores by 21.2 (95\% confidence interval 9.2, 32.2) and 11.5 (95\% CI 1.2, 22.0) than HD patients aged 1829 years, respectively. No statistically significant difference in PCS and MCS scores were found between HD patients aged $18-29$ years and those aged $30-60$ years.
As compared to female HD patients, male HD patients had higher PCS score by 8.8 points $(95 \%$ CI $3.0,14.2)$ but no statistically significant gender difference was found in MCS scores $(5.7$; 95\% CI -0.3, 11.2). HD patients with elementary and primary school education levels had lower PCS scores by 21.4 (95\% CI 14.4, 28.8) and 12.1 points $(95 \%$ CI $3.3,21.7)$ than those with education level higher than secondary school, respectively. However, no statistically significant difference in PCS scores was observed between HD patients with secondary school education level and those with education level higher than secondary school. Similar differences in MCS scores were observed among HD patients according to education level (Table 2). No statistically significant differences in PCS scores were found in relation to sociodemographic factors. However, KTRs aged 30-60 years had higher MCS scores by 7.3 (95\% CI 1.8, 12.9) than KTRs aged 18-29 years. In addition, KTRs with primary school education level had lower MCS scores by 11.0 (95\% CI 2.5, 18.7) than KTRs with education level higher than secondary school. No other statistically significant differences in MCS were observed in relation to other sociodemographic characteristics (Table 2).

\section{Differences in perceived HRQOL scores between KTRs and HD patients}

As shown in Fig. 1, KTRs had significantly higher HRQOL scores than HD patients in all SF-36 domains and subscales ranging from 22.8 (95\% CI 17.1, 28.7) for social functioning to 46.8 (95\% CI 38.3, 55.4) for rolephysical.

Table 1 Sociodemographic characteristics of kidney transplant recipients and hemodialysis patients

\begin{tabular}{|c|c|c|c|}
\hline Variable & Kidney transplant recipients $(n=100)$, number $(\%)$ & Hemodialysis patients $(n=272)$, number $(\%)$ & $p$-value \\
\hline \multicolumn{4}{|l|}{ Age group (years) } \\
\hline $18-29$ & $36(36.0)$ & $17(6.3)$ & \multirow[t]{3}{*}{$<0.001$} \\
\hline $30-60$ & $61(61.0)$ & $151(55.5)$ & \\
\hline$>60$ & $3(3.0)$ & $104(38.2)$ & \\
\hline \multicolumn{4}{|l|}{ Gender } \\
\hline Female & $25(25.0)$ & $114(41.9)$ & \multirow[t]{2}{*}{0.002} \\
\hline Male & $75(75.0)$ & $158(58.1)$ & \\
\hline \multicolumn{4}{|l|}{ Education level } \\
\hline Elementary & $23(23.0)$ & $52(19.1)$ & \multirow[t]{4}{*}{$<0.001$} \\
\hline Primary school & $5(5.0)$ & $113(41.5)$ & \\
\hline Secondary school & $40(40.0)$ & $48(17.6)$ & \\
\hline$>$ Secondary & $32(32.0)$ & $59(21.7)$ & \\
\hline \multicolumn{4}{|l|}{ Residential area } \\
\hline City & $33(33.0)$ & $76(27.9)$ & \multirow[t]{3}{*}{0.166} \\
\hline Village & $58(58.0)$ & $151(55.5)$ & \\
\hline Refugee camp & $9(9.0)$ & 45 (16.5) & \\
\hline
\end{tabular}


Table 2 Sociodemographic factors associated with physical and mental component summary scores in kidney transplant recipients and hemodialysis patients

\begin{tabular}{|c|c|c|c|c|}
\hline \multirow[t]{3}{*}{ Predictor } & \multicolumn{2}{|c|}{ Kidney transplant recipients $(n=100)$} & \multicolumn{2}{|c|}{ Hemodialysis patients $(n=272)$} \\
\hline & PCS & MCS & PCS & MCS \\
\hline & $\beta$ (BCa $95 \% \mathrm{Cl})$ & $\beta$ (BCa 95\% Cl) & $\beta(\mathrm{BCa} 95 \% \mathrm{Cl})$ & $\beta(\mathrm{BCa} 95 \% \mathrm{Cl})$ \\
\hline \multicolumn{5}{|l|}{ Age group (years) } \\
\hline $18-29$ & Ref & Ref & Ref & \\
\hline $30-60$ & $4.8(-1.2,11.6)$ & $7.3(1.8,12.9)$ & $-8.8(-19.3,1.8)$ & $-3.6(-13.9,6.8)$ \\
\hline$>60$ & $-13.8(-45.4,37.0)$ & $-9.6(-22.2,1.7)$ & $-21.2(-32.2,-9.2)$ & $-11.5(-22.0,-1.2)$ \\
\hline \multicolumn{5}{|l|}{ Gender } \\
\hline Female & Ref & Ref & Ref & \\
\hline Male & $0.2(-7.2,7.6)$ & $0.1(-7.4,8.4)$ & $8.8(3.0,14.2)$ & $5.7(-0.3,11.2)$ \\
\hline \multicolumn{5}{|l|}{ Education level } \\
\hline$>$ Secondary & Ref & & Ref & Ref \\
\hline Secondary school & $-4.3(-12.9,5.0)$ & $-5.1(-12.3,2.8)$ & $-7.7(-18.2,1.4)$ & $-7.0(-16.6,2.9)$ \\
\hline Primary school & $-10.3(-22.4,2.0)$ & $-11.0(-18.7,-2.5)$ & $-12.1(-21.7,-3.3)$ & $-11.6(-20.7,-1.9)$ \\
\hline Elementary & $-8.4(-34.6,9.4)$ & $-11.4(-37.5,9.0)$ & $-21.4(-28.8,-14.4)$ & $-18.0(-26.4,-8.4)$ \\
\hline \multicolumn{5}{|l|}{ Residential area } \\
\hline City & Ref & Ref & Ref & \\
\hline Village & $-0.5(-8.2,8.7)$ & $-6.1(-23.3,8.9)$ & $6.4(-0.8,13.5)$ & $6.5(-1.2,13.8)$ \\
\hline Refugee camp & $-6.7(-23.5,9.2)$ & $1.8(-5.2,9.1)$ & $-0.01(-9.9,9.7)$ & $1.4(-8.5,11.2)$ \\
\hline
\end{tabular}

PCS Physical component summary, MCS Mental component summary, $\beta$ Regression coefficient, $B C a$ Bias corrected accelerated, $C l$ Confidence interval, Ref Reference category

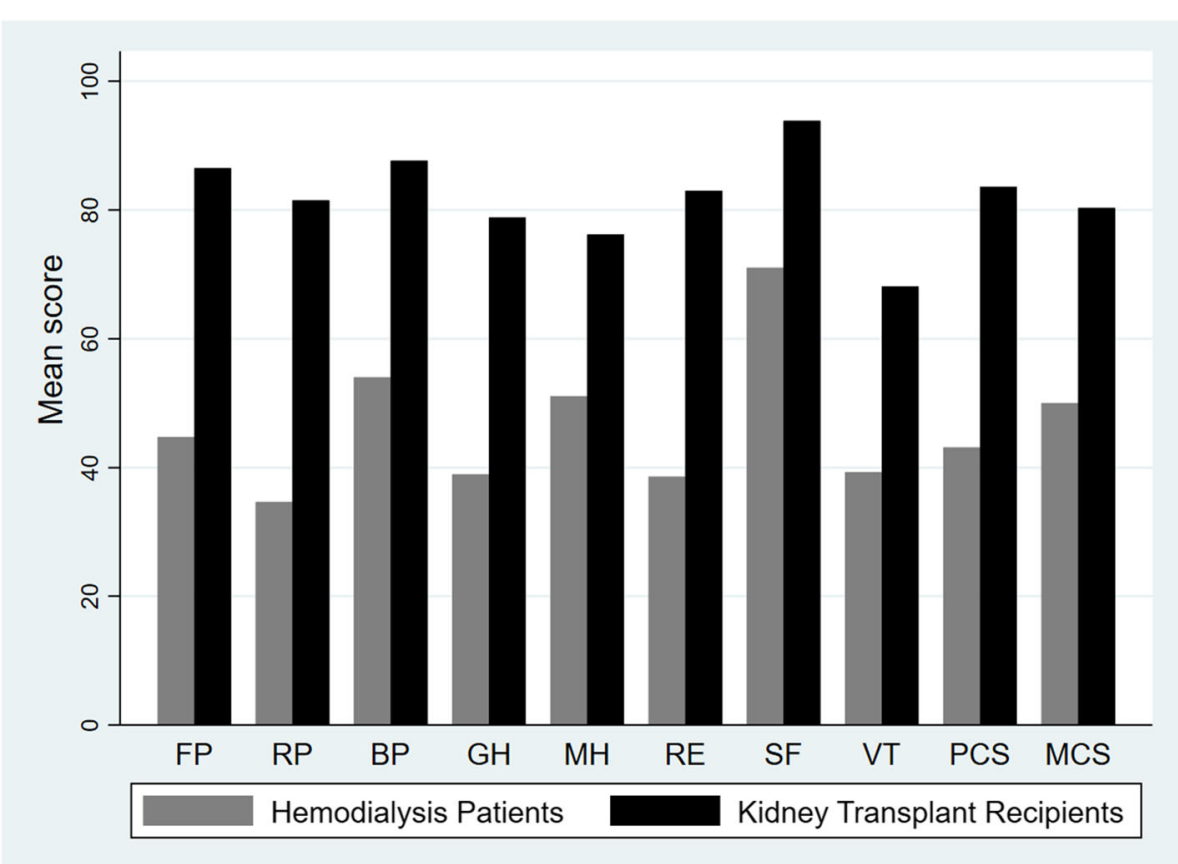

Fig. 1 Unadjusted SF-36 mean scores in kidney transplant recipients $(n=100)$ and hemodialysis patients $(n=272)$. PF, Physical functioning; RP, Role-physical; BP, Bodily pain; GH, General health; VT, Vitality; SF, Social functioning; RE, Role-emotional; MH, Mental health; PCS, Physical component summary; MCS, Mental component summary 
After adjustment for sociodemographic variables (age group, gender, education level, and residential area), KTRs had significantly higher clinically important differences in all the SF-36 domains and subscales ranging between 15.5 for social functioning (95\% CI 10.1, 20.7) and 32.6 for physical role (95\% CI 24.0, 41.1) (Table 3).

\section{Discussion}

The present study compared HRQOL in KTRs and HD patients. As compared to HD patients, KTRs were more likely to be males, younger, and have higher education levels. These results are consistent with previous studies [30, 31]. Our study showed that KTRs have significantly better HRQOL than HD patients in all the SF-36 domains and subscales ranging from 15.5 for social functioning and 32.6 for physical role. These are considered clinically important differences in comparison to the minimal clinically important "benchmark" differences in HRQOL for any health condition (3-5 points) [32], stage five CKD (6-11 points) [33], and 15 points for patients with heart disease [34].

Our findings that KTRs have better HRQOL than HD patients in all domains of HRQOL agree with previous studies [35-39]. For example, Maglakelidze and colleagues reported that Georgian KTRs had significantly better HRQOL than HD patients in all SF-36 subscales ranging between 14.2 for social functioning and 33.6 for bodily pain [36]. These findings suggest the kidney transplantation is associated with significant improvements in HRQOL, which were also observed in previous cohort studies among KTRs [38, 39]. For instance, a two-year prospective cohort study from South Korea reported significant improvements in all SF-36 domains and subscales after kidney transplantation in comparison to baseline values [38].

The present study has several strengths. First, it included a relatively large number of KTRs and HD patients from two kidney units representing $37 \%$ of all patients on renal replacement therapy in the West Bank [24]. Second, the Palestinian population is highly homogeneous in terms of ethnicity, culture, spirituality, and physical environment. Therefore, the findings are likely to be generalizable to KTRs and HD in the West Bank or other areas in the Middle East with similar socioeconomic factors and healthcare systems. This study also has some limitations. One limitation is that self-reported perceived HRQOL is considered a subjective indicator of health status and may be influenced by individual expectations of health and recovery, which may underestimate or overestimate actual healthcare outcomes. A second

Table 3 Adjusted differences in perceived HRQOL scores between kidney transplant recipients $(n=100)$ and hemodialysis patients $(n=272)$

\begin{tabular}{|c|c|c|c|}
\hline SF-36 dimensions & Group & $\beta(\mathrm{BCa} 95 \% \mathrm{Cl})^{\mathrm{a}}$ & Mean score $(95 \% \mathrm{Cl})$ \\
\hline \multirow[t]{2}{*}{ Physical functioning } & KTRs & $24.5(18.5,30.2)$ & $72.1(66.7,77.6)$ \\
\hline & HDPs & Ref & $47.7(43.9,51.4)$ \\
\hline \multirow[t]{2}{*}{ Role-physical } & KTRs & $32.6(24.0,41.1)$ & $67.8(59.8,75.7)$ \\
\hline & HDPs & Ref & $35.2(29.7,40.6)$ \\
\hline \multirow[t]{2}{*}{ Bodily pain } & KTRs & $24.8(18.2,31.4)$ & $79.6(73.6,85.5)$ \\
\hline & HDPs & Ref & $54.7(50.7,58.8)$ \\
\hline \multirow[t]{2}{*}{ General health } & KTRs & $32.4(26.9,38.3)$ & $72.5(67.2,77.8)$ \\
\hline & HDPs & Ref & $40.1(36.5,43.7)$ \\
\hline \multirow[t]{2}{*}{ Physical component summary } & KTRs & $28.6(23.6,33.7)$ & $73.0(68.1,77.8)$ \\
\hline & HDPs & Ref & $44.4(41.1,47.7)$ \\
\hline \multirow[t]{2}{*}{ Vitality } & KTRs & $20.5(14.9,26.6)$ & $59.8(54.6,64.9)$ \\
\hline & HDPs & Ref & $39.3(35.8,42.9)$ \\
\hline \multirow[t]{2}{*}{ Social functioning } & KTRs & $15.5(10.1,20.7)$ & $87.9(82.2,93.5)$ \\
\hline & HDPs & Ref & $72.4(68.5,76.3)$ \\
\hline \multirow[t]{2}{*}{ Role-emotional } & KTRs & $29.5(20.2,39.7)$ & $68.6(59.8,77.3)$ \\
\hline & HDPs & Ref & $39.0(33.0,45.1)$ \\
\hline \multirow[t]{2}{*}{ Mental health } & KTRs & $24.5(17.5,30.6)$ & $73.7(67.5,79.8)$ \\
\hline & HDPs & Ref & $49.2(45.0,53.4)$ \\
\hline \multirow[t]{2}{*}{ Mental component summary } & KTRs & $22.5(17.6,27.5)$ & $72.5(67.7,77.3)$ \\
\hline & HDPs & Ref & $50.0(46.7,53.3)$ \\
\hline
\end{tabular}


limitation is that we collected no information on some factors associated with low HRQOL among patients with CKD, such as disease comorbidity, low body mass index, anemia, low glomerular filtration rate, and baseline HRQOL scores [37, 38]. However, we accounted for important sociodemographic variables associated with HRQOL among patients with CKD including age, gender, and education level. In addition, our findings are consistent with the findings of previous studies that accounted for those factors including socioeconomic, disease-specific factors, disease comorbidity and biochemical markers [36-38]. Another limitation is that our findings may not be generalizable to other populations and regions with different culture, religious beliefs, ethnicity, other socioeconomic factors, and healthcare systems influencing HRQOL. Finally, in the present study, we did not compare HRQOL between KTRs and a control group selected from the general population.

Further research comparing HRQOL between KTRs, patients treated with different renal replacement modalities, and the general population, with comprehensive assessment of factors affecting with HRQOL, may provide useful information about the magnitude of HRQOL attributed to kidney transplantation. This information may shed light on targeted interventions to address any modifiable factors associated with lower HRQOL among KTRs as compared to the general population.

\section{Conclusions}

This study adds further evidence that KTRs have better HRQOL than HD patients in physical and mental components of the SF-36 including physical functioning, role-physical, bodily pain, general health, vitality, social functioning, role-emotional, and mental health. Further longitudinal research comparing HRQOL among KTRs and the general population may identify key modifiable factors associated with lower HRQOL among KTRs that are amenable to intervention.

\section{Abbreviations}

Cl: Confidence interval; CKD: Chronic kidney disease; HD: Hemodialysis; HRQOL: Health related quality of life; KTRs: Kidney transplant recipients; MCS: Mental component summary; PCS: Physical component summary; SF36: 36-Item Short Form Health Survey

\section{Acknowledgments}

We thank the participating patients and the medical staff in the kidney units in Palestine Medical Complex and An-Najah National University Hospital for making the study possible.

\section{Authors' contributions}

All authors contributed to the study conception and design. Material preparation, data collection and analysis were performed by RJ, AS, and MS The first draft of the manuscript was written by AS and all authors commented on previous versions of the manuscript. All authors read and approved the final manuscript.

\section{Funding}

The publication of this article was funded by the Qatar National Library. The funder had no role in study design; collection, analysis, and interpretation of data; writing the report; and the decision to submit the report for publication.

\section{Availability of data and materials}

The datasets used and/or analysed during the current study are available from the corresponding author on reasonable request.

\section{Declarations}

Ethics approval and consent to participate

This study was performed in line with the principles of the Declaration of Helsinki. The study was ethically approved by An-Najah National University Institutional Review Board (Reference number 20/AP/0018). Written informed consent was obtained from all individual participants included in the study.

\section{Consent for publication}

Not applicable.

Competing interests

The authors have no relevant financial or non-financial interests to disclose.

\section{Author details}

${ }^{1}$ Department of Public Health, Faculty of Medicine and Health Sciences, An-Najah National University, Ramallah, Palestine. ${ }^{2}$ Palestine Medical Complex, Ministry of Health, Ramallah, Palestine. ${ }^{3}$ Department of Public Health, College of Health Sciences, QU Health, Qatar University, PO Box. 2713, Doha, Qatar.

Received: 9 February 2021 Accepted: 20 May 2021

Published online: 03 June 2021

\section{References}

1. Luyckx VA, Tonelli M, Stanifer JW. The global burden of kidney disease and the sustainable development goals. Bull World Health Organ. 2018;96(6): 414-22D. https://doi.org/10.2471/BLT.17.206441.

2. Couser WG, Remuzzi G, Mendis S, Tonelli M. The contribution of chronic kidney disease to the global burden of major noncommunicable diseases. Kidney Int. 2011;80(12):1258-70. https://doi.org/10.1038/ki.2011.368.

3. Hill NR, Fatoba ST, Oke JL, Hirst JA, O'Callaghan CA, Lasserson DS, et al. Global prevalence of chronic kidney disease - a systematic review and meta-analysis. PLoS One. 2016;11(7):e0158765. https://doi.org/10.1371/journa I.pone.0158765.

4. Babińska A, Wawrzynek W, Czech E, Skupiński J, Szczygieł J, Łabuz-Roszak B. No association between MRI changes in the lumbar spine and intensity of pain, quality of life, depressive and anxiety symptoms in patients with low back pain. Neurol Neurochir Pol. 2019;53(1):74-82. https://doi.org/10.5603/ PJNNS.a2018.0006.

5. Dalrymple LS, Katz R, Kestenbaum B, Shlipak MG, Sarnak MJ, Stehman-Breen $\mathrm{C}$, et al. Chronic kidney disease and the risk of end-stage renal disease versus death. J Gen Intern Med. 2011;26(4):379-85. https://doi.org/10.1007/ s11606-010-1511-x

6. Go AS, Yang J, Tan TC, Cabrera CS, Stefansson BV, Greasley PJ, et al. Contemporary rates and predictors of fast progression of chronic kidney disease in adults with and without diabetes mellitus. BMC Nephrol. 2018; 19(1):146.

7. Abecassis M, Bartlett ST, Collins AJ, Davis CL, Delmonico FL, Friedewald JJ, et al. Kidney transplantation as primary therapy for end-stage renal disease: a National Kidney Foundation/kidney disease outcomes quality initiative (NKF/KDOQITM) conference. Clin J Am Soc Nephrol. 2008;3(2):471-80. https://doi.org/10.2215/CJN.05021107.

8. Liyanage T, Ninomiya T, Jha V, Neal B, Patrice HM, Okpechi I, et al. Worldwide access to treatment for end-stage kidney disease: a systematic review. Lancet. 2015;385(9981):1975-82. https://doi.org/10.1016/S0140-673 6(14)61601-9.

9. Global Observatory on Donation and Transplantation International report on organ donation and transplantation activities: Executive summary 2019. Global Observatory on Donation and Transplantation; 2021. Available from: 
http://www.transplant-observatory.org/wp-content/uploads/2021/04/ glorep2019.pdf. Accessed 2 May 2021.

10. Global Observatory on Donation and Transplantation. International report on organ donation and transplantation activities: Executive summary 2018. Global Observatory on Donation and Transplantation; 2020. Available from: http://www.transplant-observatory.org/globalreport-2018/. Accessed 2 May 2021.

11. Oniscu GC, Brown $H$, Forsythe JLR. Impact of cadaveric renal transplantation on survival in patients listed for transplantation. J Am Soc Nephrol. 2005 16(6):1859-65. https://doi.org/10.1681/ASN.2004121092.

12. Kaballo MA, Canney M, O'Kelly P, Williams Y, O'Seaghdha CM, Conlon PJ. A comparative analysis of survival of patients on dialysis and after kidney transplantation. Clin Kidney J. 2018;11(3):389-93. https://doi.org/1 $0.1093 / \mathrm{ckj} / \mathrm{sf} \times 117$.

13. Chan S, Cao C, Pascoe EM, Johnson DW, Shah A, Holtmann GA, et al. Patient-reported gastrointestinal symptoms and the association with quality of life following kidney transplantation. Kidney Int Rep. 2020;6(1):138-45. https://doi.org/10.1016/j.ekir.2020.10.013.

14. Gil APP, Lunardi AC, Santana FR, Bergamim J, Sarmento LA, Cristelli MP, et al. Impact of renal transplantation and immunosuppressive therapy on muscle strength, functional capacity, and quality of life: a longitudinal study. Transplant Proc. 2020;52(5):1279-83. https://doi.org/10.1016/j.transproceed.2 020.02.038.

15. Gentile S, Beauger D, Speyer E, Jouve E, Dussol B, Jacquelinet C, et al. Factors associated with health-related quality of life in renal transplant recipients: results of a national survey in France. Health Qual Life Outcomes. 2013;11(1):88. https://doi.org/10.1186/1477-7525-11-88.

16. Thiruchelvam PT, Willicombe M, Hakim N, Taube D, Papalois V. Renal transplantation. Bmj. 2011;343(nov14 1):d7300. https://doi.org/10.1136/bmj. d7300.

17. Mapes DL, Lopes AA, Satayathum S, McCullough KP, Goodkin DA, Locatelli $F$, et al. Health-related quality of life as a predictor of mortality and hospitalization: the Dialysis outcomes and practice patterns study (DOPPS). Kidney Int. 2003;64(1):339-49. https://doi.org/10.1046/j.1523-1755.2003. 00072.x.

18. Lowrie EG, Curtin RB, LePain N, Schatell D. Medical outcomes study short form-36: a consistent and powerful predictor of morbidity and mortality in dialysis patients. Am J Kidney Dis. 2003;41(6):1286-92. https://doi.org/10.101 6/S0272-6386(03)00361-5.

19. Reese PP, Bloom RD, Shults J, Thomasson A, Mussell A, Rosas SE, et al. Functional status and survival after kidney transplantation. Transplantation. 2014;97(2):189-95. https://doi.org/10.1097/TP.0b013e3182a89338.

20. von der Lippe N, Waldum B, Brekke FB, Amro AA, Reisæter AV, Os I. From dialysis to transplantation: a 5-year longitudinal study on self-reported quality of life. BMC Nephrol. 2014;15(1):191. https://doi.org/10.1186/1471-23 69-15-191.

21. Griva K, Stygall J, Ng JH, Davenport A, Harrison MJ, Newman S. Prospective changes in health-related quality of life and emotional outcomes in kidney transplantation over 6 years. J Transp Secur. 2011;2011:671571.

22. Peipert JD, Caicedo JC, Friedewald JJ, Abecassis MMI, Cella D, Ladner DP, et al. Trends and predictors of multidimensional health-related quality of life after living donor kidney transplantation. Qual Life Res. 2020;29(9):2355-74. https://doi.org/10.1007/s11136-020-02498-2.

23. Hwang Y, Kim M, Min K. Factors associated with health-related quality of life in kidney transplant recipients in Korea. PLoS One. 2021;16(3):e0247934. https://doi.org/10.1371/journal.pone.0247934.

24. Palestinian Health Information Center. Health annual report: Palestine 2017. Ramallah: Palestinian Health Information Center; 2018. Available from: http:// site.moh.ps/index/Books/BookType/2/Language/ar

25. Ware JE Jr, Gandek B. Overview of the SF-36 health survey and the international quality of life assessment (IQOLA) project. J Clin Epidemiol. 1998:51(11):903-12. https://doi.org/10.1016/S0895-4356(98)00081-X.

26. Sheikh KA, Yagoub U, Elsatouhy M, Al Sanosi R, Mohamud SA. Reliability and validity of the Arabic version of the SF-36 health survey questionnaire in population of Khat chewers-Jazan region-Kingdom of Saudi Arabia. Appl Res Qual Life. 2015;10(1):1-13. https://doi.org/10.1 007/s11482-013-9291-1.

27. Gómez-Besteiro MI, Santiago-Pérez MI, Alonso-Hernández A, Valdés-Cañedo F, Rebollo-Alvarez P. Validity and reliability of the SF-36 questionnaire in patients on the waiting list for a kidney transplant and transplant patients. Am J Nephrol. 2004;24(3):346-51. https://doi.org/10.1159/000079053.
28. Glover C, Banks P, Carson A, Martin CR, Duffy T. Understanding and assessing the impact of end-stage renal disease on quality of life: a systematic review of the content validity of self-administered instruments used to assess health-related quality of life in end-stage renal disease. Patient. 2011;4(1):19-30. https://doi.org/10.2165/11584650-000000000-00000.

29. de Brito DCS, Machado EL, Reis IA, Moreira DP, Nébias THM, Cherchiglia ML. Modality transition on renal replacement therapy and quality of life of patients: a 10-year follow-up cohort study. Qual Life Res. 2019;28(6):1485-95. https://doi.org/10.1007/s11136-019-02113-z

30. Dweib K, Jumaa S, Khdour M, Hallak H. Quality of life for kidney transplant palestinian patients. Saudi J Kidney Dis Transplant. 2020;31(2):473-81. https://doi.org/10.4103/1319-2442.284023.

31. Ogutmen B, Yildirim A, Sever MS, Bozfakioglu S, Ataman R, Erek E, et al. Health-related quality of life after kidney transplantation in comparison intermittent hemodialysis, peritoneal dialysis, and normal controls. Transplant Proc. 2006;38(2):419-21. https://doi.org/10.1016/j.transproceed.2 006.01.016.

32. Samsa G, Edelman D, Rothman ML, Williams GR, Lipscomb J, Matchar D. Determining clinically important differences in health status measures: a general approach with illustration to the health utilities index mark II. Pharmacoeconomics. 1999;15(2):141-55. https://doi.org/10.2165/00019053-1 99915020-00003.

33. Erez $\mathrm{G}$, Selman L, Murtagh FE. Measuring health-related quality of life in patients with conservatively managed stage 5 chronic kidney disease: limitations of the medical outcomes study short form 36: SF-36. Qual Life Res. 2016;25(11):2799-809. https://doi.org/10.1007/s11136-016-1313-7.

34. Wyrwich KW, Spertus JA, Kroenke K, Tierney WM, Babu AN, Wolinsky FD. Clinically important differences in health status for patients with heart disease: an expert consensus panel report. Am Heart J. 2004;147(4):615-22. https://doi.org/10.1016/j.ahj.2003.10.039.

35. Liem YS, Bosch JL, Arends LR, Heijenbrok-Kal MH, Hunink MG. Quality of life assessed with the medical outcomes study short form 36-item health survey of patients on renal replacement therapy: a systematic review and meta-analysis. Value Health. 2007;10(5):390-7. https://doi.org/10.1111/j.1 524-4733.2007.00193.x

36. Maglakelidze N, Pantsulaia T, Tchokhonelidze I, Managadze L, Chkhotua A. Assessment of health-related quality of life in renal transplant recipients and dialysis patients. Transplant Proc. 2011;43(1):376-9. https://doi.org/10.1016/j. transproceed.2010.12.015.

37. Czyżewski L, Sańko-Resmer J, Wyzgał J, Kurowski A. Assessment of healthrelated quality of life of patients after kidney transplantation in comparison with hemodialysis and peritoneal dialysis. Ann Transplant. 2014;19:576-85. https://doi.org/10.12659/AOT.891265.

38. Lim HJ, Koo TY, Lee J, Huh KH, Park JB, Cho J, et al. Health-related quality of life of kidney transplantation patients: results from the KoreaN cohort study for outcome in patients with kidney transplantation (KNOW-KT) study. Transplant Proc. 2016;48(3):844-7. https://doi.org/10.1016/j.transproceed.201 5.12.101.

39. Balaska A, Pistolas D, Koukoulaki M, Alassas D, Drakopoulos S, Kaklamanos I, et al. Changes in health-related quality of life in Greek adult patients two years after successful renal transplantation. BANTAO J. 2016;14(1):30-3. https://doi.org/10.1515/bj-2016-0007.

\section{Publisher's Note}

Springer Nature remains neutral with regard to jurisdictional claims in published maps and institutional affiliations.

Ready to submit your research? Choose BMC and benefit from:

- fast, convenient online submission

- thorough peer review by experienced researchers in your field

- rapid publication on acceptance

- support for research data, including large and complex data types

- gold Open Access which fosters wider collaboration and increased citations

- maximum visibility for your research: over $100 \mathrm{M}$ website views per year

At $\mathrm{BMC}$, research is always in progress.

Learn more biomedcentral.com/submission 